\title{
The Association between Early Dental Visits, Dental Outcomes, and Oral Health-Related Quality of Life in West Virginia Children
}

Jennifer Momen

Follow this and additional works at: https://researchrepository.wvu.edu/etd

\section{Recommended Citation}

Momen, Jennifer, "The Association between Early Dental Visits, Dental Outcomes, and Oral Health-Related Quality of Life in West Virginia Children" (2016). Graduate Theses, Dissertations, and Problem Reports. 6248.

https://researchrepository.wvu.edu/etd/6248

This Thesis is protected by copyright and/or related rights. It has been brought to you by the The Research Repository @ WVU with permission from the rights-holder(s). You are free to use this Thesis in any way that is permitted by the copyright and related rights legislation that applies to your use. For other uses you must obtain permission from the rights-holder(s) directly, unless additional rights are indicated by a Creative Commons license in the record and/ or on the work itself. This Thesis has been accepted for inclusion in WVU Graduate Theses, Dissertations, and Problem Reports collection by an authorized administrator of The Research Repository @ WVU. For more information, please contact researchrepository@mail.wvu.edu. 
The Association between Early Dental Visits, Dental Outcomes, and Oral Health-Related Quality of Life in West Virginia Children

\author{
Jennifer Momen \\ Thesis submitted to the School of Public Health \\ at West Virginia University \\ in partial fulfillment of the requirements for the degree of \\ Master of Public Health in \\ Social and Behavioral Sciences \\ Ranjita Misra, Ph.D., CHES, FASHA, Chair \\ Keith Zullig, M.S.P.H., Ph.D., FASHA \\ R. Constance Wiener, DMD, Ph. D. \\ School of Public Health \\ Department of Social and Behavioral Sciences
}

Morgantown, West Virginia

2016

Keywords: children, oral health, dental caries, dental visit

Copyright 2016 Jennifer Momen 


\begin{abstract}
The Association between Early Dental Visits, Dental Outcomes, and

Oral Health-Related Quality of Life in West Virginia Children
\end{abstract}

Jennifer Momen

Background and objectives:

Early dental visits provide the opportunity to reduce the prevalence of early childhood caries through risk assessment, counseling, and provision of specific preventive measures. Despite the American Academy of Pediatric Dentistry's recommendation that the first dental visit should occur by 1 year of age, many children are not receiving care until much later. Evidence that early dental visits improve dental outcomes is vital to educate parents and health care providers. Hence, this study examined the association between a child's age at the first dental visit and dental outcomes, parents' awareness of the recommendation for the first dental visit, and perceived barriers to dental care. A secondary aim examined pediatric dentists' perceived barriers to children's early dental care in West Virginia.

Methods:

A cross-sectional survey was used to collect data from parents of children $\leq 6$ years of age, and under the care of a pediatric dentist. Pearson correlation was used to examine the association between age at first dental visit and age at caries onset. Chi-square analyses were used to test the association between (1) age at first dental visit and history of caries, (2) age at first dental visit and history of an adverse dental outcome, and (3) reason for the first dental visit and history of an adverse dental outcome. A binary logistic regression model was used to evaluate the extent to which age at the first dental visit explained caries history. For the qualitative study component, pediatric dentists responded to questions regarding barriers to the establishment of a dental home for West Virginia children.

Results:

A significant association was noted between a child's age at the first dental visit and age at caries onset, $\mathrm{r}(29)=0.65, \mathrm{p}<.0001[95 \% \mathrm{CI}=0.39,0.82]$. No significant association was noted between age at the first dental visit and history of caries, or between age at first visit and history of adverse outcome $(\mathrm{p}>.05)$. However, children whose first visit was for a problem with the teeth or mouth were significantly more likely to have had an adverse outcome, $\chi^{2}(1, \mathrm{n}=160)=$ $7.60, \mathrm{p}=.0058$. The adjusted odds ratio for age at first dental visit in the logistic regression model predicting caries history was $1.10,[95 \% \mathrm{CI}=1.04,1.17], \mathrm{p}=.0013$. Pediatric dentists perceived the limited dental workforce in West Virginia to be the greatest barrier to early dental visits for children.

Conclusions:

This pilot study demonstrates that parent reported dental outcomes may be useful in studies evaluating the association between early dental visits and dental outcomes. There remains a need to educate parents about the recommended first dental visit by age 1 year. 


\section{Acknowledgments}

I would like to thank my committee members, Dr. Keith Zullig and Dr. R. Constance Wiener, and committee chair, Dr. Ranjita Misra for sharing their knowledge with me, and for their support and guidance throughout this study.

I wish also to thank the pediatric dentists of West Virginia who made this study possible by offering the survey to parents of their patients and responding to questions for the qualitative component of the study. Finally, I would like to acknowledge the dental office staff who handled the day to day administration of the survey while managing busy dental practices. 
This thesis is dedicated to my husband, Moe and my daughter, Sarah for their support and patience throughout this project. 
Table of Contents

List of tables $\quad$ V

Introduction and Review of the Literature 1

Methods

Results 8

$\begin{array}{ll}\text { Discussion } & 20\end{array}$

$\begin{array}{ll}\text { References } & 24\end{array}$

$\begin{array}{ll}\text { Appendices } & 27\end{array}$ 


\section{List of Tables}

Table 1. Demographics of study population

Table 2. Child oral health outcomes

Table 3. Child and parent oral health behaviors

Table 4. Parent knowledge and beliefs regarding early childhood dental visits

Table 5. Chi-squared analysis by caries experience

Table 6. Logistic regression on history of dental caries

Table 7. Barriers to the establishment of a dental home for West Virginia children 
Introduction and Review of the Literature

Dental caries is the most common chronic disease of childhood, ${ }^{1,2}$ and is associated with significant medical, psychosocial, and economic consequences for children and their families. ${ }^{3,4}$ Data from the National Health and Nutrition Examination Survey (2011-2012) indicate that about 37 percent of U.S. children ages 2-8 years had dental caries experience, and that about 14 percent had untreated dental caries. ${ }^{5}$ The percentage of West Virginia children with caries experience is similarly high, and has increased in recent years. ${ }^{6}$ According to State Oral Health Survey data, the percentage of third grade children in West Virginia with caries increased from 42 percent in 2010-2011 to 56 percent in 2013-2014. ${ }^{6}$ The percentage of third grade children with untreated dental caries also increased during the same time period, from about 17 percent to about 21 percent. $^{6}$

Early childhood caries is defined as "the presence of one or more decayed (noncavitated or cavitated lesions), missing (due to caries), or filled tooth surfaces in any primary tooth in a child under the age of six." Early childhood caries is associated with significant consequences for both child and family. Children with early childhood caries have an increased risk of further dental caries, delayed growth and development, ${ }^{2,8}$ emergency department visits, hospitalizations, days lost from school, and increased treatment costs. ${ }^{7}$ If left untreated, the bacterial infection associated with caries may spread, resulting in dental abscess, bone destruction, or infection of the bloodstream. ${ }^{9}$ Several studies have demonstrated that dental decay affects a child's school attendance and/or ability to learn. ${ }^{3,10,11}$ Data from the 1989 National Health Interview Survey revealed that approximately 51 million hours of school were missed by children nationwide due to a dental problem or a visit to a dentist. ${ }^{3}$ A study of disadvantaged children in Los Angeles County found that children with untreated dental disease were four times more likely to have a low grade point average when compared with children not having unmet dental needs. ${ }^{11}$ The Early Childhood Oral Health Impact Scale (ECOHIS) was designed by Pahel and colleagues to assess the impact of dental caries on the child and the family. ${ }^{12}$ Impacts of dental disease on the child identified during development of the ECOHIS include pain, irritability, difficulty eating, difficulty with speech, and trouble sleeping. ${ }^{12}$ Impacts of childhood dental disease on the family included feelings of upset or guilt, time missed from work, and financial difficulties. ${ }^{12}$ Additionally, dental caries treatment accounts for a significant proportion of overall health care expenses for children. Griffin and colleagues reported that in 2009, about \$20 billion was spent on dental treatments for 5-17 year old children, representing 17.7 percent of all health care expenses. $^{2}$

Risk factors for early childhood caries include prior caries experience, colonization of the oral cavity with mutans streptococci (usually as a result of transmission from the primary caregiver), visible plaque on the primary teeth, dietary factors (frequent consumption of sugary foods or beverages), developmental defects in the tooth enamel, low socioeconomic status, and being an ethnic minority or recent immigrant. ${ }^{4}$ Additional caries risk factors include chronic illness, alteration in saliva volume or composition, and mouth breathing. ${ }^{9}$ Colonization of the oral cavity with mutans streptococci is likely to occur before the age of 12 months ${ }^{9}$, a fact which underscores the importance of early preventive dental visits.

Both the American Academy of Pediatrics and the American Academy of Pediatric Dentistry recommend an early preventive dental visit as an effective way to reduce the incidence of early childhood caries. ${ }^{13,14}$ The American Academy of Pediatric Dentistry Policy on the Dental Home 
was adopted in 2001 and reaffirmed in $2010 .{ }^{15}$ It states that referral for dental care by a primary care physician is recommended based on risk assessment "as early as six months of age, six months after the first tooth erupts, and no later than 12 months of age." "15 The American Academy of Pediatrics policy statement "Oral Health Risk Assessment: Timing and Establishment of the Dental Home" was first published in 2003, and recommended that pediatricians refer a child for dental care by no later than 1 year of age. ${ }^{16}$ The Academy's most recent policy statement in 2014 reaffirmed the importance of a dental visit by 1 year of age. ${ }^{17}$

Although early childhood dental visits provide an opportunity to reduce the incidence of dental caries and its complications, ${ }^{2,14,18}$ many children do not see a dentist by 12 months of age, ${ }^{2,19}$ as recommended by both the American Academy of Pediatrics ${ }^{13}$ and the American Academy of Pediatric Dentistry. ${ }^{14}$ Although the potential benefits of early preventive dental visits would seem apparent to most, evidence of their effectiveness in improving dental outcomes is relatively weak. A systematic review by the U.S. Preventive Services Task Force in 2013, for example, was unable to find any study which "directly evaluated the effects of referral by a primary care clinician to a dentist on caries incidence." 20

\section{Benefits of early preventive dental visits}

The American Academy of Pediatric Dentistry outlines a number of issues which can be addressed during early childhood dental visits. Specific recommendations for the 6 to 12 month visit include a complete oral examination (with radiographs as needed), oral hygiene counseling for parents, the assessment of need for systemic or topical fluoride, assessment of feeding practices, dietary counseling, injury prevention counseling, counseling for nonnutritive oral habits, and caries risk assessment. ${ }^{14}$ Assessment of caries risk includes an oral examination, questions related to dietary practices, exposure to systemic fluoride, oral hygiene practices, dental history of the mother or primary caretaker, socioeconomic status of the mother or primary caretaker, and identification of any special health care needs. ${ }^{21}$

Identification of behavioral caries risk factors provides an opportunity for caregiver education. Specific recommendations to caregivers should include strategies to reduce oral colonization with mutans streptococci, bacteria which metabolize sugars and produce acids which may lead to tooth decay. ${ }^{22}$ Education should also include recommendations to minimize the frequency of consumption of sugary foods or drinks, proper tooth brushing technique and frequency, and reminders about the importance of regular dental examinations and timely treatment of existing caries. ${ }^{13,23}$ Preventive dental visits also provide an opportunity for the provision of specific measures to reduce caries risk, such as the application of topical fluoride, prescription of oral fluoride supplements to at-risk children lacking an adequately fluoridated source of drinking water, and placement of sealants on teeth with pits and fissures. ${ }^{14}$

\section{Utilization of dental services in childhood}

Despite guidelines calling for the establishment of a dental home by age 1 year, few children receive dental care by the recommended age. ${ }^{24}$ Savage and colleagues (2004) found that less than $1 \%$ of Medicaid-enrolled children in North Carolina had their first preventive dental visit

before age 1 year, and less than $3 \%$ had their first visit between ages $1-2$ years. ${ }^{25}$ Medicaid data from 2008 indicate that only 9 percent of children ages 1 to 2 years have had a preventive dental 
visit. ${ }^{23}$ Medical Expenditure Panel Survey data from 2009 indicate that only 7.6 percent of children under 2 years of age had a dental visit, and that only 1.7 percent had a visit for preventive services. $^{2}$

Low utilization of dental services in childhood likely has many causes, including lack of dental insurance, limited access to dental providers, and lack of awareness among parents and medical providers of the importance of early preventive dental visits. ${ }^{26-29}$ Data from the 2011 Medical Expenditure Panel Survey indicate that only about 57 percent of children 2 to 5 years of age were offered advice for a routine dental check-up from a doctor or other health provider. ${ }^{30}$ A national survey of pediatricians reported that more than half of the pediatricians surveyed believed that "parents' lack of perceiving dental care as important" was a significant barrier to dental referral. ${ }^{28}$ Another significant barrier, identified by almost 40 percent of pediatricians, was a "lack of dentists who provide care for this young age group." 28 A 2006 study of primary care providers in Canada found that only 2.7 percent of pediatricians and family physicians recommended the first dental visit before age 1 year, and about 20 percent reported delaying the recommendation until the child was three years of age and older. ${ }^{29}$

For children covered under the Medicaid program, utilization of dental services may be improved by requiring primary care providers to adhere to best practice guidelines for oral health by referring children for dental care in accordance with recommendations. Adherence to the Medicaid Early and Periodic Screening, Diagnosis, and Treatment (EPSDT) guidelines for best oral health practices was evaluated by Hom and colleagues. ${ }^{31}$ They found that of the 32 states with EPSDT dental periodicity schedules, 31 states required referral to a dentist, but only 11 of those states adhered to best practices by requiring dental referral by age 1 year, ${ }^{31}$ with three states calling for the first dental visit by age 2 years, and another three states calling for the first visit by age 3 years. ${ }^{31}$ West Virginia is among the 11 states requiring dental referral by age 1 year. $^{31}$

\section{Existing evidence for the effectiveness of early preventive dental visits}

Relatively few studies have been designed to directly examine the association between early childhood preventive dental visits and clinical dental outcomes. Previous studies were designed to examine the outcomes of dental expenditures, the number of non-preventive dental visits, or the number of dental treatment procedures, while others have linked clinical dental outcomes to Medicaid claims data.

Dental outcomes reported in a study of Medicaid enrolled children in North Carolina included the child's age at future preventive, restorative, and/or emergency dental visits, as well as Medicaid expenditures for those visits. ${ }^{25}$ Researchers in that study found that children having a first preventive dental visit by 12 months of age were more likely to have subsequent preventive visits, but were not more likely to have subsequent restorative or emergency visits, compared with children whose first visit occurred at a later age. ${ }^{25}$ Researchers concluded that the age at the first dental visit had a significant positive effect on dental treatment expenditures, as average treatment costs were less for those receiving earlier preventive care. ${ }^{25}$ Specifically, the average dental treatment cost per child (over the five year study period) with a first preventive visit before age 1 year was $\$ 263$, while for children with a first preventive visit at age 2-3 years, the average treatment cost per child was $\$ 450 .^{25}$ 
Sen and colleagues studied children enrolled in Alabama's Children's Health Insurance Program and examined the outcome of one year lagged non-preventive dental care and non-preventive treatment expenditures. ${ }^{32}$ They found that children with more preventive dental visits had fewer subsequent non-preventive dental visits and lower non-preventive treatment expenditures. ${ }^{32}$ The study was not designed, however, to demonstrate an association between a child's age at the first preventive dental visit and need for non-preventive dental care.

Beil and colleagues compared treatment and expenditures for Medicaid-enrolled children with a preventive visit prior to age 18 months with those having a visit between ages 18-42 months, and found no differences in dental outcomes between the groups. ${ }^{33}$ They did find, however, that among children with existing dental disease, those with a visit before 18 months of age had lower rates of subsequent caries-related treatment. ${ }^{33}$

A 2014 study by Beil and colleagues demonstrated an urgent-care type of dental service utilization in Medicaid enrolled children in North Carolina. Children whose first dental visit occurred between ages 3-4 years or between ages 4-5 years were found to have less disease (as measured by the number of decayed, missing, or filled primary teeth) compared with children whose first visit occurred by age 2 years. ${ }^{18}$

A more recent study was designed to examine the impact of physician-based preventive oral health services on caries experience in kindergarten children by linking Medicaid claims with public health surveillance data. ${ }^{34}$ The authors found that children with 4 or more medical visits with comprehensive preventive oral health services (any combination of screening, counseling, or topical fluoride application) before their third birthday had fewer caries than those not receiving these services. ${ }^{34}$

\section{Study objectives and hypotheses}

Evidence that early childhood dental visits improve oral health outcomes may lead to increased numbers of children referred for dental care in accordance with current guidelines. This study was designed to examine the association between a child's age at the first dental visit and a history of dental caries, adverse dental outcome, and oral health-related quality of life. It also sought to evaluate parents' awareness of the year 1 dental visit recommendation, and their opinion of the most appropriate time for a child's first dental visit. Finally, the study sought to obtain information about the source of referral for the first dental visit, the reason for the first dental visit, and barriers to obtaining dental care for children in West Virginia as perceived by parents and pediatric dentists. Information about awareness of the dental visit recommendation, childhood dental referral patterns, and barriers to dental visits will be useful in the development of strategies to educate parents and primary care providers about the importance of early dental care, thereby increasing the number of children referred for the age 1 dental visit.

This study will test the hypothesis that there is an association between the child's age at the first dental visit and each of several outcomes-- age at onset of dental caries, history of dental caries, and history of an adverse dental outcome (dental abscess, and the need for dental treatment under sedation or general anesthesia). 
Methods

\section{Study design}

The study was a cross-sectional survey of parents of young children under the care of a pediatric dentist in West Virginia. For the qualitative component of the study, pediatric dentists responded to open-ended questions regarding barriers to the early establishment of a dental home for children in West Virginia. The study was approved by the Institutional Review Board of West Virginia University in September of 2015 (protocol number 1507758822). Surveys were collected from October 6, 2015 through February 27, 2016.

\section{Sample}

The study sample for the parental survey was comprised of parents of children $\leq 6$ years of age and under the care of a pediatric dentist in West Virginia between October, 2015 and February, 2016. The sample for the qualitative study was all pediatric dentists practicing in West Virginia in January, 2016.

\section{Recruitment of pediatric dentists}

Each of the 17 pediatric dentists practicing in West Virginia was contacted to request the opportunity to recruit participants by offering the survey to parents of children in their practice. Contact information for pediatric dentists was provided by the president of the West Virginia chapter of the American Academy of Pediatric Dentistry. Pediatric dentists were contacted by email to explain the purpose of the study and the method of data collection (Appendix A). Participating dentists provided the name of a contact person (office manager or front-office staff) who would take responsibility for administration of the survey. All pediatric dentists, irrespective of survey participation, were contacted by mail in January, 2016 to request participation in the qualitative component of the study (Appendix B). Dentists were informed that their names would not be associated with their replies in any publications associated with the study.

\section{Eligibility criteria}

Parents of children age 6 years and younger, with a dental appointment for any reason (routine visit/hygiene, consultation, or restorative procedure) were eligible to complete the anonymous survey. There were no specific exclusion criteria. Parents volunteered to answer survey questions for no more than two of their children. All practicing pediatric dentists in West Virginia were eligible to participate in the qualitative component of the study.

\section{Data collection and participant compensation}

Dental office staff were provided with standardized instructions for the administration of the survey (Appendix C), designed to be completed in the office during the child's dental visit. Parents of children meeting eligibility criteria were offered information as they signed-in for the child's appointment. The survey with a cover letter explaining the general goals of the study was provided to parents (Appendix D). The cover letter explained that the survey was anonymous, participation was voluntary, and that failure to complete the survey would have no impact on their child's dental care. Parents who volunteered to complete the survey were compensated with a package of West Virginia University temporary tattoos, and participants returning a completed survey were entered into a drawing for a \$50 Wal-Mart gift card. 
Surveys and compensation were mailed to each of the participating dental offices, and postagepaid envelopes were provided for return of completed surveys. Questions for the qualitative component of the study were mailed to each of the 17 pediatric dentists practicing in West Virginia in January of 2016. An incentive of $\$ 5$ and a postage-paid return envelope was provided at the time of the mailing.

\section{Measures}

Demographic variables included the child's age, gender, race, type of dental insurance, parent's level of education, and household income.

The main outcome variable was a history of dental caries in the child. Parents were asked to report a history of dental caries in their children ("Have you ever been told by a doctor or a dentist that your child has at least one cavity or tooth decay?"). For children with a history of dental caries, parents were asked if the child was less than age 3 years or $\geq$ age 3 years at caries onset, as well as the exact age at caries onset, if known.

A second outcome of interest was a history of an adverse dental outcome (defined as a history of dental abscess or the need for dental treatment under sedation or general anesthesia). Parents were asked to state whether the child has ever had a dental abscess or tooth infection ("An abscess is an infection in the tooth or gums which is treated with an antibiotic. Child may have had the tooth pulled as part of the treatment"), dental treatment under sedation ("Sedation means giving a medicine by mouth or through a vein (IV) to make the child sleepy"), or dental treatment under general anesthesia ("General anesthesia means the child was given medicine in the operating room to make him/her fall completely asleep and feel no pain”).

An additional outcome of interest was oral health-related quality of life, which was measured using the Early Childhood Oral Health Impact Scale (ECOHIS). The ECOHIS is a 13-item tool, with scores ranging from 13 to 65, which was designed to measure the impact of dental disease in preschool children and their families. ${ }^{12}$ Higher scores on the ECOHIS indicate greater impact of dental disease, and therefore lower oral health-related quality of life. Previous studies have demonstrated the construct validity of the ECOHIS, and have shown that it has high internal consistency and test-retest reliability. ${ }^{12}$

Independent variables included the child's age at the first dental visit as both a continuous and dichotomous variable (less than two years vs. two years and older), the reason for the child's first dental visit (routine/preventive visit vs. a problem with the teeth or mouth), the source of referral for the child's first dental visit (self, friend/family, child's physician, or family dentist), type of dental insurance (Medicaid, private, SCHIP, or none), parent dental treatment frequency (none, only with problem/sometimes, or regular visits about every 6 months), untreated dental caries in the parent (yes, no, or not sure), parent awareness of recommendation for a child's first dental visit (aware vs. not aware), parent level of education (4 levels- less than high school through graduate/professional), combined household income (5 levels- less than $\$ 15,000$ to more than $\$ 75,000$ ), child tooth brushing frequency (4 levels- less than once per day to three or more times per day), and child frequency of sweetened beverage consumption ( 5 levels- never to 5 or more times per day).

Additional variables included the parent's agreement with a statement about the importance of routine dental care for children ("A child should see a dentist for regular check-ups even if he or 
she has no problems with the teeth or mouth"), and the parent's opinion of the most appropriate age for a child's first dental visit. Parents were also asked to indicate whether they had ever had difficulty getting a dental appointment for their child, and parents reporting difficulty were asked to rate the relative importance of 7 different barriers (very important, somewhat important, or not at all important).

The qualitative component of the study consisted of four open-ended questions addressing pediatric dentists' opinions of barriers to the early establishment of a dental home for children in West Virginia, and their suggestions to reduce those barriers:

1. What are some of the barriers to the establishment of a dental home for young children in our state? Please list as many barriers as you would like, and circle the barrier which you feel is most relevant to children in West Virginia

2. What are your suggestions for eliminating or reducing some of the above barriers, so that more West Virginia children receive dental care at an early age, as recommended by the AAPD and AAP?

3. In your opinion, what are the reasons underlying low rates of referral of young children to pediatric dentists in West Virginia? Please consider referrals from primary care medical providers (pediatricians, family physicians, mid-level providers) and/or general dentists in your response.

4. What do you think is needed to increase general dentists' level of comfort in examining and/or treating young children (less than 3-4 years of age) in areas of our state with a limited pediatric dentistry workforce?

Analysis of qualitative data consisted of identification of themes which emerged from the data, and frequency counts.

Statistical analysis of all quantitative data was performed using SAS version 9.4 (SAS Institute, Inc., 2002-2012, Cary, NC). Statistical analyses were conducted using an alpha level of .01, beginning with a level of .05 and utilizing a Bonferroni correction for multiple comparisons. 
Results

\section{Descriptive statistics}

Ten of the 17 pediatric dentists practicing in West Virginia agreed to participate in the survey component of the study, representing five counties. A total of 320 parent surveys were distributed, and 126 were returned, yielding a response rate of $39.4 \%$.

\section{Study population}

Descriptive statistics of the study population are found in Table 1. A total of 126 parents completed the survey for 162 children (with 36 parents providing responses for two children). The mean age of children in the study was 53.1 months $(n=162, S D 16.4)$ with a range of 74 months. The mean age at the first dental appointment was 26.8 months $(\mathrm{n}=117, S D 11.8)$ with a range of 57 months. The mean age of children in the early first dental visit group (less than 2 years) was 48.6 months, and the mean age of children in the late first dental visit group (2 years or older) was 55.7 months. The first dental visit occurred at age 2 years or older for $70 \%$ of children.

There were 88 males $(54.3 \%)$ and 74 females (45.7\%). The majority of the children $(92.6 \%)$ were non-Hispanic White, and covered under Medicaid (48.4\%) or private dental insurance $(40.7 \%)$. Eighty-five percent of the children's first dental visit was for a routine check-up or preventive visit. Two-thirds of children's first dental appointment was self-referred; $31.1 \%$ were referred by the child's physician or dentist. 
Table 1. Demographics of study population

\begin{tabular}{|c|c|c|}
\hline & $\mathrm{N}$ (missing) ${ }^{1}$ & Number (\%) \\
\hline Gender & $162(0)$ & \\
\hline Male & & $88(54.3)$ \\
\hline Female & & $74(45.7)$ \\
\hline Race & $162(0)$ & \\
\hline White & & $150(92.6)$ \\
\hline Other & & $12(7.4)$ \\
\hline Dental insurance & $162(0)$ & \\
\hline Medicaid & & $70(48.8)$ \\
\hline Private & & $66(40.7)$ \\
\hline SCHIP & & $11(6.8)$ \\
\hline None & & $6(3.7)$ \\
\hline Parent education & $124(2)$ & \\
\hline High school or less & & $36(29.0)$ \\
\hline Some college & & $38(30.7)$ \\
\hline College & & $32(25.8)$ \\
\hline Graduate/professional & & $18(14.5)$ \\
\hline Household income & $125(1)$ & \\
\hline$<50,000$ & & $19(15.2)$ \\
\hline $50,000-75,000$ & & $13(10.4)$ \\
\hline$>75,000$ & & $93(74.4)$ \\
\hline Reason for first visit & $160(2)$ & \\
\hline Routine/preventive & & $136(85.0)$ \\
\hline Problem with teeth/mouth & & $24(15.0)$ \\
\hline Referral source for $1^{\text {st }}$ visit & $161(1)$ & \\
\hline Self/friend or family & & $111(68.9)$ \\
\hline Physician or dentist & & $50(31.1)$ \\
\hline Age at first dental visit & $160(2)$ & \\
\hline 2 years or older & & $112(70.0)$ \\
\hline Less than 2 years & & $48(30.0)$ \\
\hline
\end{tabular}




\section{Child oral health outcomes}

In children with dental caries, the mean number of caries was $3(n=37$, SD 2.64) with a range of 12. Numbers and percentages of children with a history of dental caries, history of dental abscess, and the need for dental treatment under sedation or general anesthesia are found in Table 2.

Table 2. Child oral health outcomes

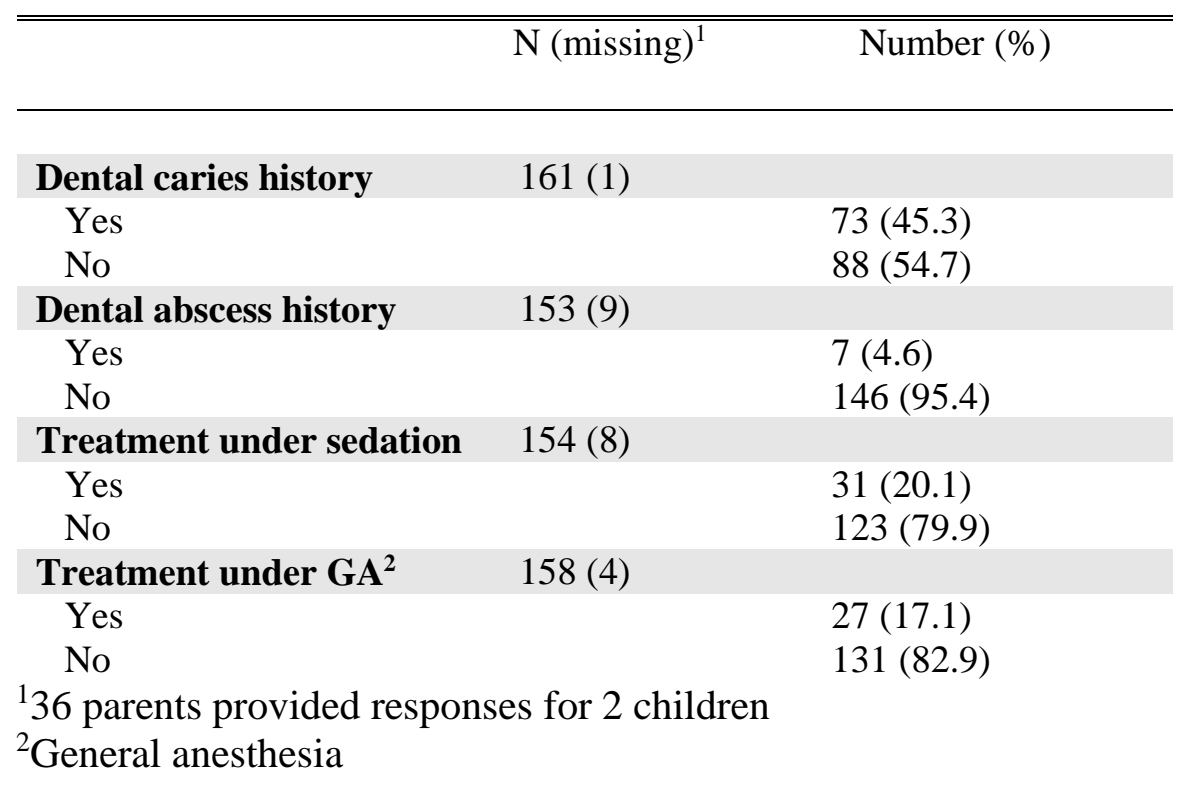

\section{Child and parent oral health behaviors}

Participants reported that $5 \%$ of children were being seen for the first dental appointment. Additionally, regular dental visits (every 6 months) were reported for almost $89 \%$ of children. More than $50 \%$ of children consumed sweetened beverages $1-2$ times per day $(53.7 \%) ; 22.2 \%$ consumed sweetened beverages 3 times per day or more. The majority of children $(71.3 \%)$ had a tooth brushing frequency of twice per day. A personal history of untreated caries was reported by $21 \%$ of parents. Child and parent oral health behavior data is provided in Table 3. 
Table 3. Child and parent oral health behaviors

\begin{tabular}{lll}
\hline \hline & N (missing) & Number (\%) \\
\hline & & \\
Child dental appointment frequency & $160(2)$ & \\
$\quad$ First appointment & & $8(5.0)$ \\
$\quad$ About every 6 months & & $142(88.8)$ \\
$\quad$ About once a year or less & $10(6.3)$ \\
Parent dental appointment frequency & $124(2)$ & \\
$\quad$ About every 6 months & & $49(39.5)$ \\
$\quad$ Sometimes, whether problem or not & & $19(15.3)$ \\
Only when problem with teeth/mouth & & $34(27.4)$ \\
$\quad$ Does not go to the dentist & $157(5)$ & $22(17.7)$ \\
Child tooth brushing behavior & & $7(4.5)$ \\
$\quad$ Less than once per day & & $34(21.7)$ \\
Once per day & $116(73.9)$ \\
Twice per day or more & & \\
Child sweetened beverage frequency & $162(0)$ & $39(24.1)$ \\
Never or rarely & & $87(53.7)$ \\
1-2 times per day & & $36(22.2)$ \\
3 times per day or more & & \\
Parent/caretaker with untreated caries & $124(2)$ & $26(21.0)$ \\
Yes & & $75(60.5)$ \\
No & & $23(18.6)$ \\
Not sure &
\end{tabular}

Parent knowledge and beliefs regarding early dental visits for children

Awareness of the recommendation for a child's first dental visit was reported by 88 parents $(71 \%)$. Among parents stating that they remember the recommended age for the first visit, the correct age (1 year) was reported by 34.9 percent.

Among parents less than age 30 years $(n=44), 66 \%$ were aware of the recommendation, and among parents age 30 years or older $(n=80), 74 \%$ were aware of the recommendation. Among parents with at least a high school education $(n=120), 73 \%$ were aware of the recommended age for the first dental visit.

Parents' opinions of the most appropriate age for a child to begin going to the dentist are shown in Table 4. Almost 50\% of parents perceived that the best age for a child to start seeing a dentist was 2 years.

The majority of parents $(84.8 \%)$ either agreed or strongly agreed with the importance of regular dental visits for children, even in the absence of a problem. 
Table 4. Parent knowledge and beliefs regarding early childhood dental visits

\begin{tabular}{|c|c|c|}
\hline & $\mathrm{N}$ (missing) & Number (\%) \\
\hline Awareness of recommendation for visit & $124(2)$ & \\
\hline Not aware & & $36(29.03)$ \\
\hline Aware but cannot recall the age & & $37(29.84)$ \\
\hline Aware and states age at first visit & & $51(41.13)$ \\
\hline Stated age for first visit ${ }^{1}$ & 63 & \\
\hline 1 year & & $22(34.9)$ \\
\hline 2 years & & $32(50.8)$ \\
\hline 3 years & & $9(14.3)$ \\
\hline Opinion for first dental visit (age) & $123(3)$ & \\
\hline 1 year & & $40(32.5)$ \\
\hline 2 years & & $61(49.6)$ \\
\hline 3 years or older & & $22(17.9)$ \\
\hline Importance of regular dental visits in childhood & $124(2)$ & \\
\hline Strongly disagrees or disagrees & & $18(14.5)$ \\
\hline Agrees & & $13(10.5)$ \\
\hline Strongly agrees & & $93(75.0)$ \\
\hline
\end{tabular}

\section{Barriers to obtaining dental visits}

Only 6 parents reported a lifetime difficulty of obtaining a dental appointment for their child. Twelve parents rated the relative importance of the seven different barriers to obtaining dental appointments (including 6 who reported not having difficulty obtaining an appointment for their child). The percentage of parents rating each barrier as either "somewhat important" or "very important" is reported below:

"I was not able to find a dentist in my area who would see someone my child's age." (92\%)

"I had no way to pay for the appointment." (67\%)

"I had no transportation to get to the dentist's office." (58\%)

"I was not able to leave work to go to the appointment." (58\%)

"The wait time for the appointment was too long." (58\%)

“The dentist's office was too far away." (58\%)

"The dentist's office did not accept my child's insurance." (50\%) 


\section{Oral health-related quality of life}

The score on the Early Childhood Oral Health Impact Scale (ECOHIS) was not normally distributed (skewness statistic of 2.1; kurtosis statistic of 5.0). Overall, a majority of parents reported little impact of dental problems on their child or the family. With possible scores ranging between 13 and 65, the mean ECOHIS score was $16.2(\mathrm{n}=159, S D$ 4.6), with a median of 14 , and a range of 26 . Items with the highest impact (reported by parents as occurring "occasionally", "often", or "very often"), and percentage of parents reporting, are listed below:

"How often have you or another family member felt guilty because of your child's dental problems or dental treatment?" (14\%)

"How often have you or another family member been upset because of your child's dental problems or dental treatment?” (12\%)

"How often have you or another family member taken time off from work because of your child's dental problems or dental treatments?" (11\%)

"How often has your child had pain in the teeth, mouth, or jaws?" (10\%)

\section{Association between age at first dental visit and age at caries onset}

A Pearson correlation was used to test the association between a child's age at the first dental visit and the age at which dental caries was first recognized (null hypothesis $\rho=0$ ), using a twotailed alpha, $p=0.01$. A significant positive correlation was noted between age at first dental visit and age at caries onset, $\mathrm{r}(29)=0.65, \mathrm{p}<.0001[95 \% \mathrm{CI}=0.39,0.82]$, with a coefficient of determination $\left(\mathrm{r}^{2}\right)$ of 0.42 ; the null hypothesis was rejected. Children with earlier first dental visits tended to have earlier onset of dental caries.

\section{Association between age at first dental visit and history of dental caries}

Chi-square analysis was used to test the association between a child's age at the first dental visit (less than 2 years vs. 2 years and older) and a history of dental caries. The null hypothesis that there is no association between age at first dental visit and a history of dental caries was tested using an alpha level of .01 for significance. There was no significant association between age at first dental visit and history of dental caries, $\chi^{2}(1, \mathrm{n}=159)=1.56, \mathrm{p}=.21$. Children with a first dental visit at less than 2 years of age were slightly less likely to have a history of dental caries (38\%), compared with those having a first visit at 2 years or older (49\%), though this was not statistically significant $(\mathrm{p}=0.21)$.

The frequencies and percentages of children with caries experience for additional study variables are provided in Table 5 . 
Table 5. Chi-squared analysis by caries experience

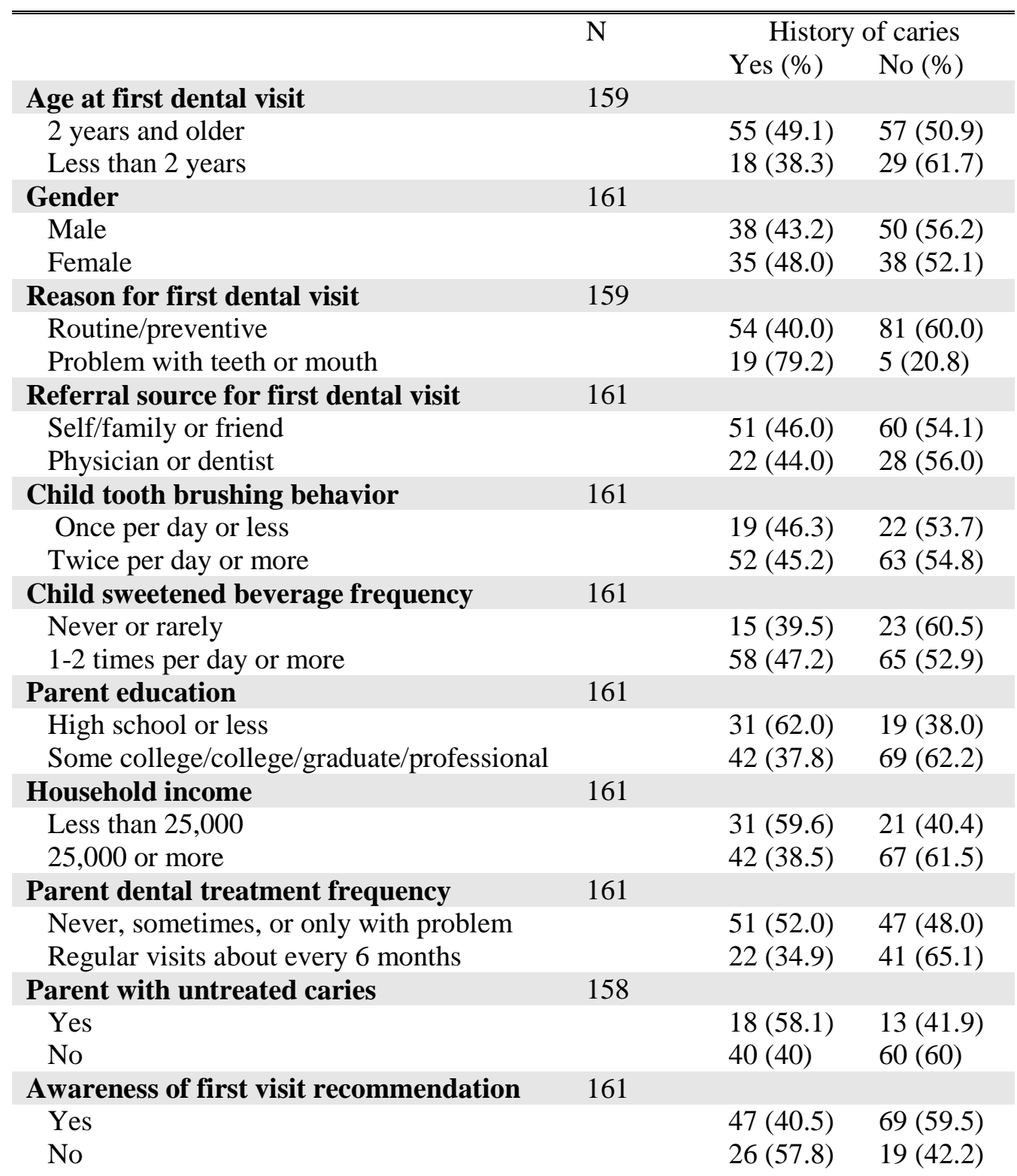

\section{Association between age at first dental visit and history of adverse dental outcome}

Chi-square analysis was used to test the association between a child's age at the first dental visit (less than 2 years vs. 2 years and older) and a history of an adverse dental outcome (dental abscess or the need for dental treatment under sedation or general anesthesia). The null hypothesis that there is no association between age at the first dental visit and history of an adverse dental outcome was tested using an alpha level of .01 for significance. No significant association was noted between age at first dental visit and a history of one of the three adverse outcomes, $\chi^{2}(1, \mathrm{n}=160)=0.42, \mathrm{p}=.52$. Children with a first dental visit at less than 2 years of age were similar in their history of an adverse outcome (27\%), compared with those having a first visit at 2 years or older $(22 \%)$. 


\section{Association between the reason for the first dental visit and adverse dental outcomes}

Chi-square analysis was used to test the association between the reason for a child's first dental visit (routine check-up/preventive visit vs. problem with the teeth or mouth) and a history of an adverse dental outcome as defined above. The null hypothesis that there is no association between the reason for the first dental visit and a history of adverse dental outcome was tested using an alpha level of 0.01 for significance. There was a significant association between the reason for a child's first dental visit and a history of adverse dental outcome, $\chi^{2}(1, \mathrm{n}=160)=$ $7.60, \mathrm{p} .0058$. Children whose first visit was for a problem with the teeth or mouth were more likely to have a history of an adverse dental outcome. The effect size was small to medium (phi coefficient of 0.22 ).

\section{Logistic regression on history of dental caries}

A logistic regression (binary logit model, Fisher's scoring technique) was used to evaluate the degree to which the child's age (in months) at the first dental appointment explained the binary outcome of dental caries history, while controlling for other variables, including the reason for the first visit, child sweetened beverage consumption frequency, presence of untreated caries in the parent, parent awareness of the first visit recommendation, and parent education. The null hypothesis that the odds ratio for the child's age at the first dental visit is equal to 1 was tested at an alpha level of .01. Unadjusted and adjusted odds ratio for the regression model are shown in Table 6. Assumptions of logistic regression were met for the model. Two observations were deleted as they were outliers in leverage, discrepancy, and influence. The overall model was not significant at an alpha level of .01 , Wald $\chi^{2}(9, \mathrm{n}=90)=19.94, \mathrm{p}=.018$. The odds ratio for age at first dental visit was significant, $\mathrm{OR}=1.10,95 \% \mathrm{CI}(1.04,1.17), \mathrm{p}=.0013$, as was the odds ratio for parent education (high school or less vs. graduate/professional), OR=15.87, 95\% CI (2.27111.12), $\mathrm{p}=.0054$. In other words, the age at first dental visit (in months) significantly predicted the history of dental caries. Every month of delay in the first visit increased the risk of dental caries by $10 \%$. Children whose first visit to the dentist was for a problem with the teeth or mouth were 6.9 times more likely to report a history of dental caries (OR $=6.9$, [95\% CI 1.22, 39.05]). Low parental education and lack of awareness of the first visit recommendation also significantly increased the risk of dental caries (Table 6).

\section{History of adverse dental outcome}

Among children whose reason for the first dental visit was routine/preventive $(n=136), 27$ children $(20 \%)$ had a history of an adverse outcome, and among those whose first dental visit was for a problem with the teeth or mouth $(n=24), 11$ children $(46 \%)$ had a history of an adverse outcome. Among children whose parent was aware of the first visit recommendation $(n=113)$, 20 children (18\%) had a history of an adverse outcome, while among those whose parent was not aware of the recommendation $(n=45), 18$ children $(40 \%)$ had a history of an adverse outcome. A history of an adverse outcome was found in 9 children $(29 \%)$ whose parent reported untreated dental caries $(n=31)$, and in 20 children $(20 \%)$ whose parent denied untreated caries $(n=100)$. For children consuming sweetened beverages never or rarely $(n=39), 9$ children $(23 \%)$ had a history of adverse outcome, for those consuming sweetened beverages 1-2 times per day $(\mathrm{n}=86)$, 16 children (19\%) had an adverse outcome, and for those consuming sweetened beverages 3 times per day or more $(n=36), 13$ children $(36 \%)$ had a history of an adverse dental outcome. 
Table 6. Logistic regression on history of dental caries

\begin{tabular}{|c|c|c|c|c|}
\hline & $\begin{array}{c}\text { Unadjusted OR }{ }^{1} \\
(95 \% \mathrm{CI})\end{array}$ & p-value & $\begin{array}{c}\text { Adjusted OR }{ }^{2} \\
(95 \% \mathrm{CI})\end{array}$ & p-value \\
\hline \multirow{2}{*}{ Age at first dental visit (months) } & & .012 & & .0013 \\
\hline & $\begin{array}{c}1.05 \\
(1.010-1.084)\end{array}$ & & $\begin{array}{c}1.10 \\
(1.04-1.17)\end{array}$ & \\
\hline Reason for first dental visit & & .0010 & & .029 \\
\hline Routine/preventive & Reference & & Reference & \\
\hline Problem with teeth or mouth & $\begin{array}{c}5.74 \\
(2.018-16.30)\end{array}$ & .0010 & $\begin{array}{c}6.90 \\
(1.22-39.05)\end{array}$ & \\
\hline $\begin{array}{l}\text { Aware of first visit } \\
\text { recommendation }\end{array}$ & & .024 & & .025 \\
\hline Aware & Reference & & Reference & \\
\hline Not aware & $\begin{array}{c}2.27 \\
(1.11-4.61)\end{array}$ & .024 & $\begin{array}{c}4.32 \\
(1.21-15.47)\end{array}$ & \\
\hline $\begin{array}{l}\text { Parent with untreated dental } \\
\text { caries }\end{array}$ & & .080 & & .73 \\
\hline No & Reference & & Reference & \\
\hline Yes & $\begin{array}{c}2.08 \\
(0.92-4.71)\end{array}$ & .080 & $\begin{array}{c}1.27 \\
(0.34-4.78)\end{array}$ & \\
\hline $\begin{array}{l}\text { Child sweetened beverage } \\
\text { frequency }\end{array}$ & & .016 & & .015 \\
\hline Never/rarely & Reference & & Reference & \\
\hline 1-2 times per day & $\begin{array}{c}0.98 \\
(0.45-2.15)\end{array}$ & 0.97 & $\begin{array}{c}0.16 \\
(0.033-0.75)\end{array}$ & .020 \\
\hline 3 times per day or more & $\begin{array}{c}3.21 \\
(1.21-8.45)\end{array}$ & 0.19 & $\begin{array}{c}1.41 \\
(0.16-12.27)\end{array}$ & .75 \\
\hline Parent education & & .068 & & .047 \\
\hline Graduate/professional & Reference & & Reference & \\
\hline College & $\begin{array}{c}1.55 \\
(0.53-4.58)\end{array}$ & .42 & $\begin{array}{c}3.08 \\
(0.65-14.46)\end{array}$ & .16 \\
\hline Some college & $\begin{array}{c}1.68 \\
(0.58-4.88)\end{array}$ & .34 & $\begin{array}{c}2.98 \\
(0.52-16.94)\end{array}$ & .22 \\
\hline High school or less & $\begin{array}{c}3.58 \\
(1.25-10.28)\end{array}$ & .018 & $\begin{array}{c}15.87 \\
(2.27-111.12)\end{array}$ & .0054 \\
\hline
\end{tabular}

Model significance Wald $\chi^{2}(9, n=90)=19.94, p=.018$

${ }^{1}$ Unadjusted odds ratios reflect the association between dental caries history and each of the covariates separately

${ }^{2}$ Adjusted odds ratios reflect the association between dental caries history and each variable, controlling for all of the other variables in the model 


\section{Qualitative analysis}

Fifteen of seventeen pediatric dentists practicing in West Virginia provided answers to the questions about barriers to the establishment of a dental home for children in their first year (response rate of $88.2 \%$ ). Table 7 lists the most frequently reported themes in response to each question.

Table 7. Pediatric dentists' views on barriers to the establishment of a dental home for West Virginia children by one year of age $(\mathrm{N}=15)$

What are some of the barriers to the establishment of a dental home for young children in West Virginia?

1. Limited dentistry workforce $12(80)$

2. Low Medicaid reimbursement $9(60)$

Parent lack education about dental issues $\quad 9$ (60)

3. Lack of transportation 7 (46.7)

$\begin{array}{ll}\text { Dental health not valued by parents } & 7(46.7)\end{array}$

Irresponsible parenting 7 (46.7)

4. Physician lack of dental education/not aware of guidelines

5. Cost/finances 5 (33.3)

What are your suggestions for eliminating these barriers so that more West Virginia children receive care at an early age, as recommended by the AAPD and the AAP?

1. System of accountability for those receiving state funds 12 (80)

2. Educate parents $11(73.3)$

3. Increase Medicaid reimbursement $6(40)$

4. Educate physicians 5 (33.3)

What are the reasons underlying the low rates of referral of young children to pediatric dentists in West Virginia?

1. Lack of awareness of need for early visit/recommendation for first visit 8 (53.3)

2. General dentists fear loss of patients 7 (46.7)

3. Dental care not perceived as needed/teeth not a priority $6(40)$

What is needed in order to increase general dentists' level of comfort in examining and/or treating children less than 3-4 years of age in areas of West Virginia with a limited pediatric dentistry workforce?

1. Continuing dental education

2. More pediatric dental education in dental school 
In addition to identifying barriers to establishment of a dental home for young children, pediatric dentists were asked to indicate the barrier most relevant to children in West Virginia. One-third of dentists identified workforce issues (lack of providers accepting Medicaid, and lack of providers willing to treat young children) as the single most relevant barrier to the establishment of a dental home for young West Virginia children.

A predominant theme among pediatric dentists' responses regarding barriers to the establishment of a dental home was education. Dentists identified a need for more education of parents, physicians, and general dentists regarding childhood oral health issues. Another theme was that dental health is not valued by parents and physicians. One respondent wrote, "If primary medical providers truly saw the value of early referrals to dentists then they would refer. Doctors don't consider oral health important because they didn't learn about it in school." Another wrote, "Some primary care physicians perhaps don't see the need. They'll wait until there's a problem, then refer." Lack of responsibility of parents, and the need for accountability for those receiving state funds (Medicaid or SCHIP) were also frequently identified factors.

The theme of accountability was prominent when dentists were asked to provide suggestions to help eliminate the barriers to a dental home for West Virginia children. One of the specific recommendations was to develop a system for verification of preventive dental visits for those receiving state funds, with enforcement of penalties for parents who fail to bring their children for dental visits. One dentist wrote, "Medicaid needs to keep track of missed appointments and consequences need enforced. Things that are free have no value." Another wrote, "Medicaid needs to drug test parents." Increasing Medicaid reimbursement was a common theme, as was education of parents, physicians, and general dentists about oral health issues. Suggestions for educating parents about oral health issues included provision of literature at prenatal visits or the Women, Infants, and Children (WIC) office, billboards, and via pediatricians and general dentists. Several of the suggestions for education of pediatricians mentioned increasing awareness of the age for the first dental visit (1 year), and encouraging early referral for dental care.

With regard to possible reasons for the low rates of referral of young children to pediatric dentists by both physicians and general dentists, one of the more common themes was lack of awareness of the need for early dental visits. One dentist stated, “...medical providers may not be aware of what pediatric dentists provide compared to general dentists. Pediatric dentists are better utilized in other states." Another responded, "Perhaps again, not thinking of teeth as a priority- PCPs have so many things to cover in well checks, easy to assume that child/parents follow through with dental care." A common perception among pediatric dentists was that general dentists do not refer young children to pediatric dentists because they fear losing the child and possibly siblings as patients. As one dentist stated, "As for general dentists, they tend to want to treat the child themselves and therefore tell the parent it's OK to wait until age 3." Lack of pediatric dental knowledge on the part of physicians and general dentist was another prominent theme. One dentist responded, "Medical providers are not trained to identify early oral health issues. Referrals are not made until decay is a major problem."

When pediatric dentists were asked what is needed in order to increase general dentists' level of comfort in caring for young children in areas with a limited pediatric dentistry workforce, 
education and increased reimbursement were commonly reported themes. Specific recommendations for education of general dentists included increased focus on pediatric dental issues in dental school (including instruction in the "lap to lap exam"), continuing education courses (including behavior management, tips to help parents with modeling behavior, anticipatory guidance, use of fluoride, identification of children with high caries risk, and the importance of early dental treatment), spending time with a pediatric dentist, and a "mini-residency" in pediatric dentistry. One pediatric dentist felt that continuing dental education covering pediatric dental issues should be mandatory, and another suggested that continuing education courses might be provided by the county or state. 


\section{Discussion}

The study results are consistent with findings of previous researchers who found that the majority of children do not see a dentist until well beyond the recommended age of 1 year. ${ }^{35,36}$ The mean age for the first dental visit for children in this study (26.8 months) was close to the mean age reported by Kuthy and colleagues in 2014 (25.6 months). ${ }^{35}$ Until more children receive early dental visits, an association between age at first dental visit and history of dental caries or other adverse dental outcomes, if present, will be difficult to demonstrate.

The prevalence of dental caries $(45.3 \%)$ in the study sample (children 6 years and younger), though not directly comparable, was somewhat higher than that seen among 2-8 year olds in the United States $(37 \%){ }^{37}$ The percentage of children with an early dental visit (less than 2 years of age) in this study (30\%) was much higher than that reported in a study of North Carolina Medicaid-enrolled kindergarten children $(5.5 \%)$. ${ }^{18}$ This is most likely related to the nature of the study samples, with the recruitment of children under the care of a pediatric dentist for this study. The percentage of children with early dental visits in the state of West Virginia as a whole are likely much lower.

The significant positive correlation between a child's age at the first dental visit and age at caries onset found in this study is consistent with results of a previous study which found that children with earlier first dental visits had higher rates of untreated dental disease compared with those having first visits at a later age. ${ }^{18}$ The authors noted that these findings might be explained by the fact that children at high risk for dental caries may have been more likely to have been referred for dental care at an earlier age, and that childhood dental visits may have followed an urgent care pattern of utilization, whereby dental care was sought for the evaluation of an existing problem. ${ }^{18}$ In addition, the finding may be explained in part by noting that children with earlier first dental visits are more likely to have dental caries identified at its earliest stages.

A significant association between a child's age at the first dental visit and a history of dental caries or between age at first visit and history of an adverse dental outcome was not noted in this study. However, it is worth noting that among children with a first dental visit before 2 years of age, only $38 \%$ had a history of dental caries, while among those with a first visit at 2 years of age or older, the rate increased to $49 \%$. An important confounding factor in this analysis is that the prevalence of dental caries increases with age. ${ }^{1,38}$ The mean age of children in the late first visit group was 55.7 months, compared with 48.6 months in the early first visit group. Therefore children in the late first visit group (those 2 years of age and older) would be expected to have a higher prevalence of dental caries, and a difference in caries prevalence between the groups cannot be attributed to timing of the first dental visit. A larger sample size, and/or limiting the sample to children of a particular age (5-6 years) would help to control this confounding effect.

The finding that children presenting for a problem with the teeth or mouth were significantly more likely to have a history of an adverse dental outcome is an interesting one. This result might be expected, given that children presenting to a dentist for a problem with the teeth or mouth (pain, cavities, spots on the teeth, injury, missing tooth, or other problem) are more likely to have preexisting dental disease. However, it is nonetheless consistent with the presumption that early preventive dental care can decrease the risk of additional complications such as dental abscess or the need for more extensive treatment under sedation or general anesthesia. Given the risks to the child associated with sedation and general anesthesia, as well as the associated 
increased treatment costs, and potential time lost from work for parents, this is not an insignificant finding.

The logistic regression model on the outcome of dental caries suggests that the child's age in months at the first dental visit is a significant explanatory predictor of dental caries history (adjusted odds ratio of 1.10), when controlling for the reason for the first dental visit, frequency of sweetened beverage consumption, parent education, parent untreated cavity status, and parent awareness of the first visit recommendation. The model suggests that when controlling for the variables above, every one month increase in a child's age at the first dental visit is associated with a $10 \%$ increase in the odds of having a history of dental caries. Because the reason for the first dental visit was significantly associated with the outcome of dental caries (unadjusted odds ratio of 5.74 for problem vs. routine visit), this was an important control variable. The model may be improved in future studies by utilizing a larger sample size, providing the opportunity to control for additional confounding variables without the loss of statistical significance associated with higher degrees of freedom in such models. Potential confounding variables include household income, geographic location, regularity of dental visits, the number of preventive dental visits, and the number of topical fluoride treatments. ${ }^{35}$ Data regarding child's immunization status (whether or not child was up to date on routine immunizations) was collected for this study with the intention of using it a control variable in the regression model. In theory, parents who bring their children for regular well-child exams (including immunizations) are more likely to be attentive to proper oral hygiene practices (including regular tooth brushing and avoidance of cariogenic foods and drinks). Only $2.5 \%$ of parents in this study, however, reported that their child was not up to date on immunizations, perhaps as a result of social desirability bias, precluding its use as a control variable. Controlling for the child's frequency of well-child visits or dental visit frequency for other family members ${ }^{35}$ in future studies may allow for control of this potential confounding of parent attentiveness to the child's overall health status and oral health hygiene habits.

A somewhat surprising finding of this study was that only 6 parents reported difficulty obtaining a dental visit for their child. Parents may have felt that the question related to difficulty scheduling an appointment with the child's current dentist. More likely, though, it reflects the bias of sampling from the population of parents of children who have already established a dental home. Though the number of parents rating the relative barriers to dental care was very small, it is interesting to note that the most relevant barrier (inability to find a dentist who would care for a young child) was also the most commonly reported by pediatric dentists, and the one identified as most relevant to children in West Virginia by five of the dentists.

Barriers to the establishment of a dental home for West Virginia children reported by pediatric dentists throughout the state are consistent with those identified in earlier studies. Several of the most frequently reported barriers in this study (limited dentistry workforce, low Medicaid reimbursement/lack of dentists accepting Medicaid, transportation problems, and dental health not valued by parents) were also identified in a national survey of pediatricians. ${ }^{28}$ Low Medicaid reimbursement was viewed as a significant barrier to the establishment of a dental home for West Virginia children. A lack of dentists accepting Medicaid patients has been reported as a significant barrier by several other studies. ${ }^{26,28,39}$ West Virginia pediatric dentists responding to this survey felt that physicians are lacking in education regarding dental issues in general, and specifically, awareness of the year 1 dental visit guideline, a finding which was also supported by the national survey of pediatricians, ${ }^{28}$ and a survey of Canadian pediatricians and family 
physicians. ${ }^{29}$ Lack of awareness of the guideline for the first dental visit was supported by another national study of pediatricians, which found that only $14.6 \%$ of respondents agreed with referral to a dentist by 12 months of age. ${ }^{39}$ The perception of pediatric dentists in West Virginia that parents do not value dental care was also identified as a barrier to carrying out oral healthrelated activities by Canadian pediatricians and family physicians. ${ }^{29}$ This lack of value is also evident in the survey item regarding level of agreement with a statement about the importance of regular dental visits for children, even in the absence of a problem with the teeth or mouth. Slightly more than $14 \%$ of parents either disagreed or disagreed strongly with that statement. A barrier to dental care which was not specified in the literature, but noted in this study, is parent lack of responsibility. Related to the theme of lack of parent responsibility is the belief of some pediatric dentists that there needs to be a system of accountability for those who receive state funds via Medicaid or the state Children's Health Insurance Program (SCHIP).

There are several important limitations to this study. One is its reliance on parent reported dental outcomes, rather than previously documented or directly observed clinical dental outcomes. Parent reported outcomes and oral health behaviors are subject to both recall bias and social desirability bias. Another limitation to this study is the potential for selection bias. The study design did not include collection of data needed to evaluate the extent that parents accepting the survey differed from those not accepting the survey. Parents were limited to providing data for only two of their children, introducing the possibility for social desirability bias. Parents with three or more children under age 6 years might have chosen to report data for the two children with better dental outcomes or earlier dental visits. Each of these biases may contribute to decreased validity of the study results. The cross-sectional design of the study does not allow any inferences to be made regarding causality. Specifically, with respect to the association between age at the first dental appointment and history of dental caries demonstrated in the regression model, a causal relationship between age and dental caries history cannot be presumed, and there may be other unidentified confounding variables (for example differences in dietary practices). The inability of this study to demonstrate a relationship between age at the first dental visit and history of an adverse dental outcome may be due to a combination of the low frequency of adverse events in this population and the small sample size. Another limitation is that the survey instrument was not tested for reliability and validity prior to its use in this population. A final limitation is that this study is not generalizable to the general population of children in West Virginia, as the sample consisted only of parents whose children were already under the care of a pediatric dentist, and included dental practices from only 5 counties.

Children in this sample may differ in important ways from those not under the care of a pediatric dentist, as well as from those living in other regions of the state (for example in their risk for dental caries, dietary practices, and/or oral hygiene habits). The intent of sampling parents of children in pediatric dental practices, however, was to obtain data from a larger number of children receiving early dental visits, facilitating statistical analysis between early and late visit groups.

A positive correlation between a child's age at the first dental visit and the age at caries onset was noted in this study (children with early dental visits tend to have earlier onset of dental caries, when present). Though not statistically significant, the study also suggests that among children age 6 years and younger, those with dental visits before age 2 years are less likely to have a history of dental caries. The logistic regression model demonstrates that the child's age at the first dental visit was a significant predictor of the outcome of dental caries. 
Increasing awareness of the year 1 dental visit recommendation among parents of young children, physicians, and general dentists remains a significant need. Evidence of the benefits of early preventive dental visits for children will be an important part of efforts to increase the number of children with a dental home by 1 year of age, in accordance with the American Academy of Pediatric Dentistry guidelines. Physicians are more likely to refer children for early dental visits when they perceive a clear benefit to the child and family. Further studies are needed linking the age at the first preventive dental visit to clinical dental outcomes. The use of parent reported dental outcomes is promising, but poses significant challenges. Previous studies have used Medicaid claims data to link dental outcomes to the timing and number of preventive dental visits, and given the high percentage of West Virginia children with Medicaid insurance, this may be a useful approach. Successful implementation of the year 1 dental visit recommendation requires coordination and cooperation among parents, physicians, and dentists, and future studies should continue to examine dental outcomes which are meaningful to each of these groups, regardless of the data source. 


\section{References}

1. Maintaining and improving the oral health of young children. Pediatrics. 2014;134(6):1224-1229.

2. Griffin SO, Barker LK, Wei L, Li CH, Albuquerque MS, Gooch BF. Use of dental care and effective preventive services in preventing tooth decay among U.S. Children and adolescents--Medical Expenditure Panel Survey, United States, 2003-2009 and National Health and Nutrition Examination Survey, United States, 2005-2010. MMWR Surveill Summ. 2014;63 Suppl 2:54-60.

3. Gift HC, Reisine ST, Larach DC. The social impact of dental problems and visits. Am J Public Health. 1992;82(12):1663-1668.

4. Tinanoff N, Reisine S. Update on early childhood caries since the Surgeon General's Report. Acad Pediatr. 2009;9(6):396-403.

5. Dye BA. Dental caries and sealant prevalence in children and adolescents in the United States, 2011-2012. 2015; http://www.cdc.gov/nchs/data/databriefs/db191.htm. Accessed 07/03/2015.

6. Oral Health Data. 2013; http://nccd.cdc.gov/OralHealthData/rdPage.aspx?rdReport=DOH DATA.ExploreByLocation\&rdP rocessAction=\&SaveFileGenerated=1\&rdCSRFKey=9d54fdf9-4863-43d0-93d20e946cab5172\&isILocation=54\&ic|Topic rdExpandedCollapsedHistory=\&iclTopic=CHD\&is/Year= 2013\&hidLocation=54\&hidTopic=CHD\&hidYear=2013\&irbShowFootnotes=Show\&icllndicators $r$ dExpandedCollapsedHistory=\&icllndicators=CHD1 1\%2cCHD1 2\%2cCHD1 3\&hidPreviouslySele

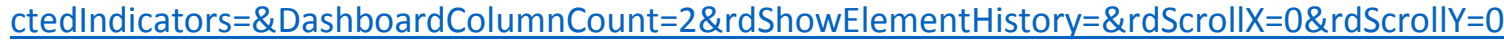
\&rdRnd=77682. Accessed April 4, 2016.

7. Policy on Early Childhood Caries (ECC): Classifications, Consequences, and Preventive Strategies. Oral Health Policies [Reference Manual]. 2015;

http://www.aapd.org/media/Policies Guidelines/P ECCClassifications.pdf. Accessed 07/03/2015.

8. Yost J, Li Y. Promoting oral health from birth through childhood: prevention of early childhood caries. MCN Am J Matern Child Nurs. 2008;33(1):17-23; quiz 24-15.

9. Oral Health in America: A Report of the Surgeon General. 2015; http://www.ncbi.nlm.nih.gov/pubmed/. Accessed 07/03/2015.

10. Blumenshine SL, Vann WF, Gizlice Z, Lee JY. Children's school performance: impact of general and oral health. J Public Health Dent. 2008;68(2):82-87.

11. Seirawan $\mathrm{H}$, Faust $\mathrm{S}$, Mulligan R. The impact of oral health on the academic performance of disadvantaged children. Am J Public Health. 2012;102(9):1729-1734.

12. Pahel BT, Rozier RG, Slade GD. Parental perceptions of children's oral health: the Early Childhood Oral Health Impact Scale (ECOHIS). Health Qual Life Outcomes. 2007;5:6.

13. Hale KJ. Oral health risk assessment timing and establishment of the dental home. Pediatrics. 2003;111(5 Pt 1):1113-1116.

14. Guideline on Periodicity of Examination, Preventive Dental Services, Anticipatory Guidance/Counseling, and Oral Treatment for Infants, Children, and Adolescents. Reference Manual 2015; Volume 36/Number

6:http://www.aapd.org/media/Policies Guidelines/G Periodicity.pdf. Accessed February 15, 2015.

15. Policy on the Dental Home. 2015; http://www.aapd.org/media/Policies Guidelines/P DentalHome.pdf. Accessed 07/05/2015.

16. Oral Health Risk Assessment Timing and Establishment of the Dental Home. Pediatrics. 2003;111(5):1113-1116.

17. Maintaining and Improving the Oral Health of Young Children. 2015; http://pediatrics.aappublications.org/content/134/6/1224.full.pdf. Accessed 07/05/2015. 
18. Beil H, Rozier RG, Preisser JS, Stearns SC, Lee JY. Effects of early dental office visits on dental caries experience. Am J Public Health. 2014;104(10):1979-1985.

19. Camargo MB, Barros AJ, Frazão $P$, et al. Predictors of dental visits for routine check-ups and for the resolution of problems among preschool children. Rev Saude Publica. 2012;46(1):87-97.

20. Chou R, Cantor A, Zakher B, Mitchell JP, Pappas M. Preventing dental caries in children $<5$ years: systematic review updating USPSTF recommendation. Pediatrics. 2013;132(2):332-350.

21. Guideline on Caries-risk Assessment and Management for Infants, Children, and Adolescents. AAPD Reference Manual 2015; http://www.aapd.org/media/Policies Guidelines/G CariesRiskAssessment.pdf. Accessed 07/03/2015.

22. Gussy MG, Waters EG, Walsh O, Kilpatrick NM. Early childhood caries: current evidence for aetiology and prevention. J Paediatr Child Health. 2006;42(1-2):37-43.

23. Douglass JD, Clark MB. Integrating Oral Health into Overall Health Care to Prevent Early Childhood Caries: Need, Evidence, and Solutions. Pediatric Dentistry. 2015;37(3):266-274.

24. Chi DL, Momany ET, Jones MP, et al. Relationship between medical well baby visits and first dental examinations for young children in Medicaid. Am J Public Health. 2013;103(2):347-354.

25. Savage MF, Lee JY, Kotch JB, Vann WF, Jr. Early preventive dental visits: effects on subsequent utilization and costs. Pediatrics. 2004;114(4):e418-423.

26. dela Cruz GG, Rozier RG, Slade G. Dental screening and referral of young children by pediatric primary care providers. Pediatrics. 2004;114(5):e642-652.

27. Ismail AI, Nainar SM, Sohn W. Children's first dental visit: attitudes and practices of US pediatricans and family physicians. Pediatr Dent. 2003;25(5):425-430.

28. Lewis CW, Boulter S, Keels MA, et al. Oral health and pediatricians: results of a national survey. Acad Pediatr. 2009;9(6):457-461.

29. Prakash P, Lawrence HP, Harvey BJ, Mclsaac WJ, Limeback H, Leake JL. Early childhood caries and infant oral health: Paediatricians' and family physicians' knowledge, practices and training. Paediatr Child Health. 2006;11(3):151-157.

30. Soni A. STATISTICAL BRIEF \#432: Children's Dental Care: Advice and Visits, Ages 2-17, 2011. 2015; http://meps.ahrq.gov/mepsweb/data files/publications/st432/stat432.shtml.

31. Hom JM, Lee JY, Silverman J, Casamassimo PS. State Medicaid Early and Periodic Screening, Diagnosis, and Treatment guidelines: adherence to professionally recommended best oral health practices. J Am Dent Assoc. 2013;144(3):297-305.

32. Sen B, Blackburn J, Morrisey MA, et al. Effectiveness of preventive dental visits in reducing nonpreventive dental visits and expenditures. Pediatrics. 2013;131(6):1107-1113.

33. Beil H, Rozier RG, Preisser JS, Stearns SC, Lee JY. Effect of early preventive dental visits on subsequent dental treatment and expenditures. Med Care. 2012;50(9):749-756.

34. Kranz AM, Preisser JS, Rozier RG. Effects of Physician-Based Preventive Oral Health Services on Dental Caries. Pediatrics. 2015;136(1):107-114.

35. Kuthy RA, Jones $M$, Kavand $G$, et al. Time until first dental caries for young children first seen in Federally Qualified Health Centers: a retrospective cohort study. Community Dent Oral Epidemiol. 2014;42(4):300-310.

36. Kagihara LE, Niederhauser VP, Stark M. Assessment, management, and prevention of early childhood caries. J Am Acad Nurse Pract. 2009;21(1):1-10.

37. Dye BA, Thornton-Evans G. Dental Caries and Sealant Prevalence in Children and Adolescents in the United States, 2011-2012. 2015; http://www.cdc.gov/nchs/data/databriefs/db191.htm. Accessed March 10, 2016.

38. Peterson-Sweeney K, Stevens J. Optimizing the health of infants and children: their oral health counts! J Pediatr Nurs. 2010;25(4):244-249. 
39. Lewis CW, Grossman DC, Domoto PK, Deyo RA. The role of the pediatrician in the oral health of children: A national survey. Pediatrics. 2000;106(6):E84. 
Appendix A. E-mail recruiting pediatric dentists for survey component of study

Subject: WVU childhood oral health study- Help needed!

Dear Dr. INSERT NAME,

I had the pleasure of meeting some of your colleagues at the state dental conference at the Greenbrier this past July, and want to introduce myself to you as well. My name is Jennifer Momen. I am a pediatrician, and I am currently pursuing a Master of Public Health degree through WVU School of Public Health. Some of you may know my husband, Moe, a pediatric dentist practicing in Bridgeport.

As part of my MPH thesis, I'm conducting a study which involves a survey of parents of young children. The survey is designed to examine the association between a child's age at the first dental visit and parent-reported dental outcomes and oral health-related quality of life, with the goal of increasing the evidence base for the establishment of a dental home in early childhood in accordance with AAP and AAPD recommendations. The study protocol was approved by the WVU Institutional Review Board, so I am ready to begin the data collection process. This is where I really need your help!

The study involves no interaction with children or access to office records, and consists only of parent responses to a brief paper survey. No personally-identifiable information will be collected. The survey is designed to be completed while a parent waits in the office (10 minutes), and parents who accept the survey will be given a small token in appreciation of their time.

I am interested in whether you would be willing to allow the survey to be handed out to parents of children aged 6 years and under who are seen in your office for any reason during the approximately 2 month data collection period (November and December). I sincerely hope you will consider participating in this study. You and your office will be acknowledged in any publications which (hopefully!) result from this study. I truly cannot obtain the data without your help. My hope is that that although this study is small and preliminary, it will open a dialog about the importance of early dental visits in childhood, and set the stage for future research leading to the goal of increasing the number of West Virginia children with early dental visits, and to the ultimate goal of improved oral health.

If you are interested in helping with this study, please let me know by responding to this email as soon as possible. If interested, you may also want to provide me with the name of one or two of your front-office staff so that I can talk with them about the specifics of the survey administration. Please call me with questions at any time. Thank you in advance for your consideration. I hope to hear from you soon!

Sincerely,

Jennifer

Jennifer Momen, MD, FAAP

Medical Director, Associate Professor

Physician Assistant Studies Program

Alderson Broaddus University

MPH candidate, WVU School of Public Health

jimomen@mix.wvu.edu

(O) 304-457-6382

(C) $304-657-4960$ 
Appendix B. Letter recruiting pediatric dentists for qualitative component of study

January 18, 2016

Dear Dr. Smith,

Thank you again for assisting with my MPH thesis by making my survey available to patients in your office. Another component of my study is to examine the relative importance of barriers to obtaining dental care for young children, and possible mechanisms to increase the number of children with a dental home by 12 months of age, in accordance with the AAPD and AAP recommendations.

I would greatly appreciate your response to four brief, open-ended questions, which are enclosed. Your name will not be associated with your replies in my thesis or any publications which result from the study. The questions include your perception of barriers to obtaining dental care for children in our state, possible reasons for low rates of referral to pediatric dentists, and your suggestions to increase the number of referrals to pediatric dentists and to improve general dentists' level of comfort in examining young children in areas with a limited pediatric dentistry workforce. You are free to answer any or all of the questions, and even brief answers will be helpful. A self-addressed, postage-paid envelope is enclosed for your convenience. I would be happy to share with you the results of the study when it is completed. Thank you in advance for your help.

Sincerely,

Jennifer

Jennifer Momen, MD, FAAP

MPH candidate, WVU School of Public Health

¿̈momen@mix.wvu.edu

\section{West VirginiaUniversity.}

SCHOOL OF PUBLIC HEALTH 
Appendix C. Survey instructions for dental office staff

Thank you so much for your help with this survey! I hope the following guidelines answer any questions you may have about handing out the survey and returning completed surveys to me, but please feel free to call or text me any time with questions. My cell number is 304-657-4960.

\section{Survey administration}

- There is no limit to the number of surveys you can hand out- the more data collected, the more valid the study results. I will supply you with as many surveys as you need.

- The survey should be offered to all parents of children 6 years old and younger who are seen in the office for any reason (routine check-up/hygiene visit, treatment, consultation). Parents may be told that the survey is part of a study designed to show the importance of dental visits for children and to increase the number of children referred for dental care.

- Parents who accept the survey can choose a package of WVU temporary tattoos as a token of appreciation. Please offer this at the same time you give the survey to the parent (not when the survey is completed). My hope is that the small gift will encourage parents to accept and complete the survey. Please keep a running tally of surveys accepted and declined (You may simply place tick marks on the enclosed tally sheet).

- Please tell parents that if they complete the whole survey, they can be entered into a drawing for a \$50 Target or Walmart gift card (their choice) by writing their name and phone number on the index card provided. You do not need to verify that the survey is completed, as I believe most people will be honest.

- You may let parents know that if they have two children 6 years old or younger, they can complete the survey for both children (the second child does not need to have an appointment on the day the survey is offered). But, if they are concerned about running out of time, it would be better to complete all questions for one child (rather than partially completing the survey for both children).

\section{$\underline{\text { Return of completed surveys }}$}

- I have provided you with postage-paid, addressed envelopes for you to return the surveys to me.

- When you have ten completed surveys, please place them in the envelope (along with the postcards for the gift card drawing) and mail them back to me.

- I will provide you with more surveys whenever needed. The study quality will be improved by obtaining as many completed surveys as possible.

Please let me know if there is anything I can do to make this process easier for you. I truly appreciate your help in making this survey available to your patients.

Jennifer

(304) 657-4960

WestVirginiaUniversity.

ïmomen@mix.wvu.edu

SCHOOL OF PUBLIC HEALTH 
Appendix D. Cover letter to parents and survey instrument

Dear Parent,

Thank you for taking the time to complete this survey, which forms the basis for my MPH thesis at West Virginia University School of Public Health. Your answers will help guide efforts to educate parents and doctors about the importance of early dental visits for children in our state. The study has been approved by the Institutional Review Board of West Virginia University.

Completing the survey should not take more than 10 minutes. The survey is anonymous- there is no way for us to identify you, or to link you to any of your answers. Your decision about whether to participate in the survey will not affect your child's dental treatment in any way. Your participation in this survey is completely voluntary, and you may stop answering questions at any time.

Please answer each of the questions about your child aged 6 years or younger. If you have two children six years of age or younger, you may complete the survey for both children. However, if you do not have time to answer all questions for both children, completing the survey for one child would be most helpful. Please let a member of the office staff know if you have any questions or concerns.

Thank you again for your help as we work towards improving dental care for all West Virginia children!

Sincerely,

Jennifer Momen, MD

Master of Public Health candidate

WVU School of Public Health

ïmomen@mix.wvu.edu 


\section{Childhood Oral Health Survey}

\begin{tabular}{|c|c|c|c|}
\hline & & Child 1 & Child 2 \\
\hline 1 & Child's age & $\ldots$ years ___ months & $\ldots$ years ___ months \\
\hline 2 & Child's gender & $\begin{array}{l}\text { Male } \quad \text { Female } \\
\text { (Please circle) }\end{array}$ & $\begin{array}{l}\text { Male } \quad \text { Female } \\
\text { (Please circle) }\end{array}$ \\
\hline 3 & Child's race & $\begin{array}{c}\text { White Black Hispanic Other } \\
\text { (Please circle) }\end{array}$ & $\begin{array}{c}\text { White Black Hispanic Other } \\
\text { (Please circle) }\end{array}$ \\
\hline 4 & $\begin{array}{l}\text { At the very first dental } \\
\text { appointment was child at } \\
\text { least } 2 \text { years old? }\end{array}$ & $\begin{array}{l}\square \text { Yes (Child was } 2 \text { years or older at } \\
\text { the first dental appointment) } \\
\square \text { No (Less than } 2 \text { years old at first } \\
\text { dental appointment) }\end{array}$ & $\begin{array}{l}\square \quad \text { Yes (Child was } 2 \text { years or older at } \\
\text { the first dental appointment) } \\
\square \quad \begin{array}{l}\text { No (Less than } 2 \text { years old at first } \\
\text { dental appointment) }\end{array}\end{array}$ \\
\hline 5 & $\begin{array}{l}\text { If you can remember, } \\
\text { exactly how old was child at } \\
\text { the very first dental } \\
\text { appointment? } \\
\text { Please think carefully, and } \\
\text { write the age to the nearest } \\
\text { year and month }\end{array}$ & $\begin{array}{c}\text { Exact age at very first dental appointment } \\
\qquad \text { Years } \_ \text {Months } \\
\square \text { I am not sure }\end{array}$ & $\begin{array}{l}\text { Exact age at very first dental appointment } \\
\qquad \text { Years } \_ \text {Months } \\
\square \quad \text { I am not sure }\end{array}$ \\
\hline 6 & $\begin{array}{l}\text { Who recommended your } \\
\text { child's very first dental } \\
\text { appointment? }\end{array}$ & $\begin{array}{ll}\square & \text { No one (myself) } \\
\square & \text { Friend or family member } \\
\square & \text { Child's medical doctor } \\
\square & \text { My dentist or family dentist }\end{array}$ & $\begin{array}{ll}\square & \text { No one (myself) } \\
\square & \text { Friend or family member } \\
\square & \text { Child's medical doctor } \\
\square & \text { My dentist or family dentist }\end{array}$ \\
\hline 7 & $\begin{array}{l}\text { What was the main reason } \\
\text { for child's very first dental } \\
\text { appointment? }\end{array}$ & $\begin{array}{l}\square \text { Routine check-up or cleaning (no } \\
\text { problems with the teeth or mouth) } \\
\square \text { Problem with the teeth or mouth } \\
\text { (pain, cavities, spots on the teeth, } \\
\text { injury, missing tooth or other } \\
\text { problem) }\end{array}$ & $\begin{array}{l}\square \text { Routine check-up or cleaning (no } \\
\text { problems with the teeth or mouth) } \\
\square \\
\text { Problem with the teeth or mouth } \\
\text { (pain, cavities, spots on the teeth, } \\
\text { injury, missing tooth or other } \\
\text { problem) }\end{array}$ \\
\hline 8 & $\begin{array}{l}\text { Have you ever been told by } \\
\text { a doctor or dentist that your } \\
\text { child has at least one cavity } \\
\text { or tooth decay? }\end{array}$ & $\begin{array}{l}\square \quad \text { Yes (please answer all remaining } \\
\text { questions) } \\
\square \quad \text { No (skip questions 9-11 in blue } \\
\text { and go on to question 12) }\end{array}$ & $\begin{array}{l}\square \quad \text { Yes (please answer all remaining } \\
\text { questions) } \\
\square \quad \text { No (skip questions 9-11 in blue } \\
\text { and go on to question 12) }\end{array}$ \\
\hline
\end{tabular}




\begin{tabular}{|c|c|c|c|}
\hline 9 & $\begin{array}{l}\text { How many cavities has child had } \\
\text { in his or her lifetime? } \\
\text { Please count all cavities, whether } \\
\text { or not they have been treated }\end{array}$ & $\begin{array}{l}\text { Please write the total number of } \\
\text { lifetime cavities in the space below: } \\
\square \quad \text { I am not sure about the } \\
\text { number of cavities }\end{array}$ & $\begin{array}{l}\text { Please write the total number of } \\
\text { lifetime cavities in the space below: } \\
\square \quad \text { I am not sure about the } \\
\text { number of cavities }\end{array}$ \\
\hline 10 & $\begin{array}{l}\text { When the first cavity was found } \\
\text { by a doctor or dentist, was the } \\
\text { child at least } 3 \text { years old? }\end{array}$ & $\begin{array}{l}\square \quad \text { Yes (at least } 3 \text { years old at } \\
\text { time of first cavity) } \\
\square \\
\text { No (less than } 3 \text { years old at } \\
\text { time of first cavity) }\end{array}$ & $\begin{array}{l}\square \quad \text { Yes (at least } 3 \text { years old at } \\
\text { time of first cavity) } \\
\square \quad \text { No (less than } 3 \text { years old at } \\
\text { time of first cavity) }\end{array}$ \\
\hline 11 & $\begin{array}{l}\text { If you can remember, please give } \\
\text { the child's exact age when a } \\
\text { cavity was first found by a doctor } \\
\text { or dentist. } \\
\text { Please think carefully, and write } \\
\text { the age to the nearest year and } \\
\text { month }\end{array}$ & $\begin{array}{l}\text { Exact age when first cavity was found } \\
\text { Years __ Months }\end{array}$ & $\begin{array}{l}\text { Exact age when first cavity was found } \\
\text { Years __ Months }\end{array}$ \\
\hline 12 & $\begin{array}{l}\text { Has child ever had a tooth abscess } \\
\text { or a tooth infection? } \\
\text { (An abscess is an infection of the } \\
\text { tooth or gums which is treated } \\
\text { with an antibiotic. Child may } \\
\text { have had the tooth pulled as part } \\
\text { of the treatment.) }\end{array}$ & $\begin{array}{l}\square \quad \text { Yes } \\
\quad \text { O How many times? } \\
\square \text { No (Child has never had a } \\
\text { tooth infection) }\end{array}$ & $\begin{array}{l}\square \quad \text { Yes } \\
\quad \circ \quad \text { How many times? } \\
\square \quad \begin{array}{l}\text { No (Child has never had a } \\
\text { tooth infection) }\end{array}\end{array}$ \\
\hline 13 & $\begin{array}{l}\text { Has child ever had any type of } \\
\text { dental treatment while under } \\
\text { sedation? } \\
\text { Sedation means giving a } \\
\text { medicine by mouth or through a } \\
\text { vein (IV) to make the child sleepy }\end{array}$ & $\begin{array}{l}\square \text { Yes (Child has had dental } \\
\text { treatment while under } \\
\text { sedation) } \\
\quad \quad \text { How many times? } \\
\square \\
\begin{array}{l}\text { No (Child has never had } \\
\text { dental treatment while under } \\
\text { sedation) }\end{array}\end{array}$ & 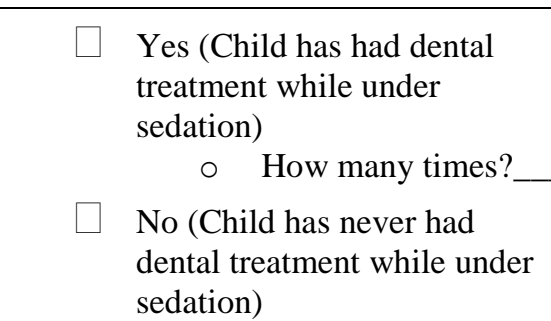 \\
\hline
\end{tabular}




\begin{tabular}{|c|c|c|c|}
\hline 14 & $\begin{array}{l}\text { Has child ever had any } \\
\text { dental treatment under } \\
\text { general anesthesia? } \\
\text { General anesthesia } \\
\text { means the child was } \\
\text { given a medicine in the } \\
\text { operating room to make } \\
\text { him/her fall completely } \\
\text { asleep and feel no pain. }\end{array}$ & $\begin{array}{c}\square \quad \text { Yes (Child had dental treatment under } \\
\text { general anesthesia) } \\
\quad \text { O How many times? } \\
\square \quad \begin{array}{l}\text { No (Child has never had dental } \\
\text { treatment under general anesthesia) }\end{array}\end{array}$ & \begin{tabular}{|l}
$\square \quad$ Yes (Child had dental treatment under \\
general anesthesia) \\
$\quad$ O How many times? \\
$\square \quad \begin{array}{l}\text { No (Child has never had dental } \\
\text { treatment under general anesthesia) }\end{array}$
\end{tabular} \\
\hline 15 & $\begin{array}{l}\text { How often does child } \\
\text { have an appointment } \\
\text { with a general dentist or } \\
\text { pediatric dentist? }\end{array}$ & $\begin{array}{l}\square \text { This is the first appointment } \\
\square \quad \text { About every } 6 \text { months } \\
\square \quad \text { About once a year } \\
\square \text { Only when there is a problem (tooth } \\
\text { or mouth pain, cavity, injury, or other } \\
\text { problem) } \\
\text { How many total dental visits has child had } \\
\text { during his or her lifetime? } \\
\end{array}$ & $\begin{array}{l}\square \quad \text { This is the first appointment } \\
\square \quad \text { About every } 6 \text { months } \\
\square \quad \text { About once a year } \\
\square \quad \text { Only when there is a problem (tooth } \\
\text { or mouth pain, cavity, injury, or other } \\
\text { problem) } \\
\text { How many total dental visits has child had } \\
\text { during his or her lifetime? } \\
\quad \text { visits }\end{array}$ \\
\hline 16 & $\begin{array}{l}\text { How long ago was } \\
\text { child's las appointment } \\
\text { with a general dentist or } \\
\text { pediatric dentist? }\end{array}$ & $\begin{array}{l}\square \quad \text { This is the first appointment } \\
\square \quad 6 \text { months ago or less } \\
\square \quad 6-12 \text { months ago } \\
\square \quad \text { More than } 12 \text { months ago }\end{array}$ & $\begin{array}{l}\square \quad \text { This is the first appointment } \\
\square \quad 6 \text { months ago or less } \\
\square \quad 6-12 \text { months ago } \\
\square \quad \text { More than } 12 \text { months ago }\end{array}$ \\
\hline 17 & $\begin{array}{l}\text { At this time is child up- } \\
\text { to-date on his/her } \\
\text { immunizations? } \\
\text { (vaccines) }\end{array}$ & $\begin{aligned} & \square \text { Yes (Child has had all vaccines } \\
& \text { recommended for his/her age) } \\
& \square \\
& \text { No (Child has not had all vaccines } \\
& \text { recommended for his/her age) }\end{aligned}$ & \begin{tabular}{|l}
$\square \quad$ Yes (Child has had all vaccines \\
recommended for his/her age) \\
$\square$ \\
No (Child has not had all vaccines \\
recommended for his/her age)
\end{tabular} \\
\hline 18 & $\begin{array}{l}\text { How many times each } \\
\text { day does child drink a } \\
\text { sweetened beverage? } \\
\text { (soda, juice, sports drink, } \\
\text { sweet tea, or other } \\
\text { sweetened beverage) }\end{array}$ & $\begin{array}{ll} & \text { Never } \\
\square & \text { Only rarely or on special occasions } \\
\square & 1-2 \text { times per day } \\
\square & 3-4 \text { times per day } \\
\square & 5 \text { or more times per day }\end{array}$ & $\begin{array}{ll}\square & \text { Never } \\
\square & \text { Only rarely or on special occasions } \\
\square & 1-2 \text { times per day } \\
\square & 3-4 \text { times per day } \\
\square & 5 \text { or more times per day }\end{array}$ \\
\hline 19 & $\begin{array}{l}\text { What type of dental } \\
\text { insurance does child } \\
\text { have? }\end{array}$ & $\begin{array}{ll}\square & \text { Medicaid } \\
\square & \text { Private insurance } \\
\square & \text { State Children's Health Insurance } \\
& \text { Program (SCHIP) } \\
\square & \text { No dental insurance }\end{array}$ & $\begin{aligned} \square & \text { Medicaid } \\
\square & \text { Private insurance } \\
\square & \text { State Children's Health Insurance } \\
& \text { Program (SCHIP) } \\
\square & \text { No dental insurance }\end{aligned}$ \\
\hline
\end{tabular}




\begin{tabular}{|l|l|l|l|}
\hline 20 & $\begin{array}{l}\text { How many times each } \\
\text { day does child brush his } \\
\text { or her teeth? (Please } \\
\text { include any times you } \\
\text { brush your child's teeth } \\
\text { or help with the } \\
\text { brushing) }\end{array}$ & $\square$ Once every day & $\square$ Twice every day \\
$\square$ More than twice every day & $\square$ Twice every day \\
\hline
\end{tabular}

The following questions will help us learn more about your views on dental care for children, and any problems you may have had in trying to get dental treatment for your child.

1. A) What is your age?

B) Your relationship to child

2. Please check the box next to the highest level of education you have completed

Less than high school

GED or high school degree

Some college (no degree)

College degree

Graduate or professional degree

3. What is your current employment status?

Not looking for work

Unemployed (looking for work)

Working part-time

Working full=time

4. Including yourself, how many people live in your household?

5. What is your current yearly (combined) household income?

Less than $\$ 15,000$

$\$ 15,000-\$ 24,999$

$\$ 25,000-\$ 49,999$

$\$ 50,000-\$ 75,000$

More than $\$ 75,000$

6. Which of the following best describes how often you go to a dentist for your own treatment?

I do not go to a dentist

I go to a dentist when I have pain or a problem with my teeth or gums

I go to a dentist sometimes, whether I have a problem or not

I try to go to the dentist regularly (about every 6 months)

7. Do you currently have any cavities which have not been treated yet? Yes No Don't know 
8. In your opinion, what is the best age for a child to go to a dentist (general or pediatric dentist) for the first time? Please write the age below

I think the best age for a child's first visit to a dentist is years

9. Are you aware of any specific recommendation for the best time for a child's first visit to a dentist?

\section{YES, and I remember the age Please write the age here:}

YES, but I do not remember the age

NO, I have not heard a recommended age for a child's first dental visit

10. Please read the statement below, and tell us how much you agree or disagree by circling one of the options below the statement.

"A child should see a dentist for regular check-ups even if he or she has no problems with the teeth or mouth."
Circle one: Strongly disagree
Disagree
No opinion
Agree
Strongly agree

11. Have you ever had difficulty getting your child an appointment with a dentist (general dentist or pediatric dentist)?

YES (Please complete questions 12-18 below)

NO (Skip questions 12-18)

\begin{tabular}{|c|l|l|l|}
\hline \multicolumn{2}{|l|}{ There are many reasons parents may find it hard to get dental appointments for their children. } \\
Circle the response which best explains the role each item played in any difficulty you have had getting a dental appointment for your child. \\
\hline $\begin{array}{l}\text { 12. I was not able to find a dentist in my area } \\
\text { who would see someone my child's age }\end{array}$ & Very important & Somewhat important & Not at all important \\
\hline $\begin{array}{l}\text { 13. I was not able to leave work to go to the } \\
\text { appointment }\end{array}$ & Very important & Somewhat important & Not at all important \\
\hline 14. I had no way to pay for the appointment & Very important & Somewhat important & Not at all important \\
\hline 15. The dentist's office was too far away & Very important & Somewhat important & Not at all important \\
\hline $\begin{array}{l}\text { 16. The dentist's office did not accept my } \\
\text { child's insurance }\end{array}$ & Very important & Somewhat important & Not at all important \\
\hline $\begin{array}{l}\text { 17. The wait time for the appointment was too } \\
\text { long }\end{array}$ & Very important & Somewhat important & Not at all important \\
\hline $\begin{array}{l}\text { 18. I had no transportation to get to the } \\
\text { appointment }\end{array}$ & Very important & &
\end{tabular}


The Early Childhood Oral Health Impact Scale: Child 1

Problems with the teeth, mouth or jaws and their treatment can affect the well-being and everyday lives of children and their families. For each of the following questions please circle the response that best describes your child's experiences or your own. Consider the child's entire life from birth until now when answering each question. If a question does not apply, circle "Never".

Please circle the response that best describes your child's experiences or your own.

1. How often has your child had pain in the teeth, mouth, or jaws?

2. How often has your child had difficulty drinking hot or cold beverages because of dental problems or dental treatments?

3. How often has your child had difficulty eating some foods because of dental problems or dental treatments?

4. How often has your child difficulty pronouncing any words because of dental problems or dental treatments?

5. How often has your child missed preschool, daycare, or school because of dental problems or dental treatments?

6. How often has your child had trouble sleeping because of dental problems or dental treatments?

7. How often has your child been irritable or frustrated because of dental problems or dental treatments?

8. How often has your child avoided smiling or laughing when around other children because of dental problems or dental treatments?

9. How often has your child avoided talking with other children because of dental problems or dental treatments?

10. How often have you or another family member been upset because of your child's dental problems or dental treatments?

11. How often have you or another family member felt guilty because of your child's dental problems or dental treatment?

12. How often have you or another family member taken time off from work because of your child's dental problems or dental treatments?

13. How often has your child had dental problems or dental treatments that had a financial impact on your family?

\begin{tabular}{|l|c|c|c|c|c|}
\hline Never & Hardly Ever & Occasionally & Often & Very Often & Don't Know \\
\hline Never & Hardly Ever & Occasionally & Often & Very Often & Don't Know \\
\hline Never & Hardly Ever & Occasionally & Often & Very Often & Don't Know \\
\hline Never & Hardly Ever & Occasionally & Often & Very Often & Don't Know \\
\hline Never & Hardly Ever & Occasionally & Often & Very Often & Don't Know \\
\hline Never & Hardly Ever & Occasionally & Often & Very Often & Don't Know \\
\hline Never & Occasionally & Often & Very Often & Don't Know \\
\hline Never & Hardly Ever & Occasionally & Often & Very Often & Don't Know \\
\hline Never & Hardly Ever & Occasionally & Often & Very Often & Don't Know \\
\hline & & & & & \\
\hline
\end{tabular}


The Early Childhood Oral Health Impact Scale: Child 2

Problems with the teeth, mouth or jaws and their treatment can affect the well-being and everyday lives of children and their families. For each of the following questions please circle the response that best describes your child's experiences or your own. Consider the child's entire life from birth until now when answering each question. If a question does not apply, circle "Never".

Please circle the response that best describes your child's experiences or your own.

14. How often has your child had pain in the teeth, mouth, or jaws?

15. How often has your child had difficulty drinking hot or cold beverages because of dental problems or dental treatments?

16. How often has your child had difficulty eating some foods because of dental problems or dental treatments?

17. How often has your child difficulty pronouncing any words because of dental problems or dental treatments?

18. How often has your child missed preschool, daycare, or school because of dental problems or dental treatments?

19. How often has your child had trouble sleeping because of dental problems or dental treatments?

20. How often has your child been irritable or frustrated because of dental problems or dental treatments?

21. How often has your child avoided smiling or laughing when around other children because of dental problems or dental treatments?

22. How often has your child avoided talking with other children because of dental problems or dental treatments?

23. How often have you or another family member been upset because of your child's dental problems or dental treatments?

24. How often have you or another family member felt guilty because of your child's dental problems or dental treatment?

25. How often have you or another family member taken time off from work because of your child's dental problems or dental treatments?

26. How often has your child had dental problems or dental treatments that had a financial impact on your family?

\begin{tabular}{|c|c|c|c|c|c|}
\hline Never & Hardly Ever & Occasionally & Often & Very Often & Don't Know \\
\hline Never & Hardly Ever & Occasionally & Often & Very Often & Don't Know \\
\hline Never & Hardly Ever & Occasionally & Often & Very Often & Don't Know \\
\hline Never & Hardly Ever & Occasionally & Often & Very Often & Don't Know \\
\hline Never & Hardly Ever & Occasionally & Often & Very Often & Don't Know \\
\hline Never & Hardly Ever & Occasionally & Often & Very Often & Don't Know \\
\hline Never & Hardly Ever & Occasionally & Often & Very Often & Don't Know \\
\hline Never & Hardly Ever & Occasionally & Often & Very Often & Don't Know \\
\hline Never & Hardly Ever & Occasionally & Often & Very Often & Don't Know \\
\hline Never & Hardly Ever & Occasionally & Often & Very Often & Don't Know \\
\hline Never & Hardly Ever & Occasionally & Often & Very Often & Don't Know \\
\hline Never & Hardly Ever & Occasionally & Often & Very Often & Don't Know \\
\hline Never & Hardly Ever & Occasionally & Often & Very Often & Don't Know \\
\hline
\end{tabular}


